\title{
A CASE STUDY
}

\section{Rainwater harvesting in North-East India: A strategy for alleviate water shortage}

\author{
SUKANTA SARKAR \\ Department of Social Science and Humanities, Faculty of Management Studies, \\ ICFAI University, AGARTALA(TRIPURA) INDIA \\ Email:sukantaeco@gmail.com
}

\begin{abstract}
Rainwater harvesting provides an independent water supply during regional water restrictions and in developed countries. There are different ways in which rainwater can be harvested. This water can be used for direct consumption as also for recharging groundwater through simple filtration devices. Water can be collected in tanks that have cement slabs built at their base to prevent the water from seeping underground. Rainwater harvesting is more popular in Meghalaya and Mizoram. The main objectives of the paper are: (a) To study the importance of rainwater harvesting; and (b) To identify the situation of rainwater harvesting in Northeastern India.
\end{abstract}

Key Words : Rainwater harvesting, Meghalaya, Mizoram, Water shortage

View Point Article : Sarkar, Sukanta (2017). Rainwater harvesting in North-East India: A strategy for alleviate water shortage. Internat. J. agric. Sci., 13 (2) : 434-436, DOI:10.15740/HAS/IJAS/13.2/434-436.

Article History : Received : 23.01.2017; Accepted : 30.05 .2017 